Research

\title{
Blockade of Wnt-I signaling leads to anti-tumor effects in hepatocellular carcinoma cells Wei Wei ${ }^{1}$, Mei-Sze Chua*1, Susan Grepper ${ }^{2}$ and Samuel K So ${ }^{1}$
}

\author{
Address: ${ }^{1}$ Asian Liver Center, Department of Surgery, Stanford University School of Medicine, Stanford, CA 94305, USA and ${ }^{2}$ CellzDirect/ \\ Invitrogen, 4301 Emperor Blvd, Durham, NC 27703, USA \\ Email: Wei Wei - weiwei25@stanford.edu; Mei-Sze Chua* - mchua@stanford.edu; Susan Grepper - sue.grepper@lifetech.com; \\ Samuel K So - samso@stanford.edu \\ * Corresponding author
}

Published: 24 September 2009

Molecular Cancer 2009, 8:76 doi:10.1 186/1476-4598-8-76
Received: 6 August 2009

Accepted: 24 September 2009

This article is available from: http://www.molecular-cancer.com/content/8/I/76

(C) 2009 Wei et al; licensee BioMed Central Ltd.

This is an Open Access article distributed under the terms of the Creative Commons Attribution License (http://creativecommons.org/licenses/by/2.0), which permits unrestricted use, distribution, and reproduction in any medium, provided the original work is properly cited.

\begin{abstract}
Background: Hepatocellular carcinoma (HCC) is an aggressive cancer, and is the third leading cause of cancer death worldwide. Standard therapy is ineffective partly because HCC is intrinsically resistant to conventional chemotherapy. Its poor prognosis and limited treatment options make it critical to develop novel and selective chemotherapeutic agents. Since the $\mathrm{Wnt} / \beta$-catenin pathway is essential in HCC carcinogenesis, we studied the inhibition of Wnt-I-mediated signaling as a potential molecular target in HCC.
\end{abstract}

Results: We demonstrated that Wnt-I is highly expressed in human hepatoma cell lines and a subgroup of human HCC tissues compared to paired adjacent non-tumor tissues. An anti-Wnt-I antibody dose-dependently decreased viability and proliferation of Huh7 and Hep40 cells overexpressing Wnt-I and harboring wild type $\beta$-catenin, but did not affect normal hepatocytes with undetectable Wnt-I expression. Apoptosis was also observed in Huh7 and Hep40 cells after treatment with anti-Wnt-I antibody. In these two cell lines, the anti-Wnt-I antibody decreased $\beta$ catenin/Tcf4 transcriptional activities, which were associated with down-regulation of the endogenous $\beta$-catenin/Tcf4 target genes c-Myc, cyclin DI, and survivin. Intratumoral injection of anti-Wnt-I antibody suppressed in vivo tumor growth in a Huh7 xenograft model, which was also associated with apoptosis and reduced c-Myc, cyclin DI, and survivin expressions.

Conclusion: Our results suggest that Wnt-I is a survival factor for HCC cells, and that the blockade of Wnt-I-mediated signaling may offer a potential pathway-specific therapeutic strategy for the treatment of a subgroup of HCC that over-expresses Wnt-I.

\section{Background}

Hepatocellular carcinoma (HCC) is the primary form of human adult liver cancer. It is the fifth most common cancer worldwide, with about one million new cases diagnosed annually, and almost an equal number of deaths. It is predominant in China, most parts of South East Asia, and South Africa, where hepatitis B virus (HBV) infection is endemic [1]. The last decade has seen no major advances in the treatment of HCC. Approximately 10$25 \%$ of HCC patients are candidates for surgical resection and liver transplantation; the majority of patients have limited treatment options due to the lack of effective chemotherapy against this intrinsically resistant tumor [24]. New pharmacological interventions that offer even 
modest improvements in efficacy and disease outcome are eagerly sought.

The Wnt/ $\beta$-catenin pathway plays an important role in embryogenesis and carcinogenesis $[5,6]$. Secreted proteins of the Wnt family bind to specific Frizzled (FZD) receptors on the surface of target cells to activate distinct intracellular pathways, resulting in the accumulation and nuclear localization of the $\beta$-catenin protein. Nuclear $\beta$-catenin binds to T-cell factor 4 (Tcf4) to drive activation of specific target genes including cyclin D1, c-Myc, and survivin, which have been characterized to be critical for cancer development [7-9]. Clinical studies have reported that abnormal activation of $\mathrm{Wnt} / \beta$-catenin pathway is frequently involved in hepatocarcinogenesis. About 33-67\% of HCC tissues show accumulation of $\beta$-catenin in the cytoplasm and nucleus, whereas no accumulation was observed in the corresponding normal tissues $[10,11]$. In addition, FZD7, a receptor for Wnt ligands, was reported to be involved in HCC development and progression $[12,13]$.

The Wnt-1 ligand has been reported to be abnormally expressed in a variety of human cancers including HCC $[14,15]$. In HCC, proteomics results suggested that enhanced Wnt-1 expression associated with NF-kB might be an important mechanism underlying hepatocarcinogenesis [16]. Moreover, transgenic mice model suggested that high expression of Wnt- 1 could be the major cause for nuclear accumulation of $\beta$-catenin, which subsequently contributes to c-myc/E2F1-driven hepatocarcinogenesis [17]. Elevated levels of tumor Wnt-1 protein in HBV- and hepatitis C virus (HCV)-related HCC has recently been shown to be a prognostic indicator of HCC recurrence after surgical resection [18]. Because of the functional importance of Wnt-1 in HCC development and progression, we investigated the anti-tumor effects of blocking Wnt-1 mediated signaling through the Wnt/ $\beta$ catenin pathway in human HCC. By using a polyclonal anti-Wnt-1 antibody, we studied the effects of Wnt-1 blockade on HCC cell growth in vitro and in vivo, and the effects on Wnt/ $\beta$-catenin mediated transcriptional activity in HCC cells.

\section{Results \\ Over-expression of Wnt-I protein in HCC tissue specimens and cell lines}

To confirm the expression of Wnt-1 protein in HCC, we used the anti-Wnt-1 antibody to detect its expression in seven pairs of HCC tissues and their corresponding adjacent non-tumor tissues. These tissues were obtained with informed consent from seven HCC patients undergoing surgical resection at Stanford Hospital. Expression of Wnt1 in HCC tissues was at least 1.5 fold greater than in paired non-tumor tissues in four out of the seven tissue pairs (Fig. 1A). Despite the small sample size, our data closely reflect that reported recently by Lee et al [18], who observed that 26 of 63 HCC patients had tumor/nontumor Wnt- 1 expression ratio of $\geq 1.5$, whereas 37 of 63 had a ratio of $<1.5$. Wnt-1 protein expression was in general higher in human HCC cell lines (Huh7, Hep40, and HepG2), but was undetectable in normal hepatocytes cultured from three different donors (Hu4122, Hu4074, Hu0910) (Fig. 1B). In general, our observations corroborate with published reports that Wnt-1 is upregulated in HBV- and HCV-related HCC tissues and cell lines $[16,19]$.

\section{Anti-Wnt-I antibody decreases cell proliferation and induces apoptosis in HCC cell lines}

The over-expression of Wnt-1 in HCC implies that Wnt-1 may be involved in hepatocellular carcinogenesis, and may be critical for the growth of HCC cells. We therefore further studied its potential as a therapeutic target for HCC treatment. After $72 \mathrm{hr}$ exposure, the anti-Wnt- 1 antibody dose-dependently decreased cell viability in Huh7 and Hep40 cells, but not in HepG2 cells and normal hepatocytes from three different donors (Fig. 2A and 2B). The lack of activity against HepG2 cells may be due to the presence of truncated $\beta$-catenin (with loss of the GSK-3 $\beta$ regulatory site) in these cells, which therefore escapes regulation by upstream events [20]. As a specificity control, we examined the effect on cell proliferation of overnight pre-incubation of the anti-Wnt-1 antibody with its specific blocking peptide (at 20-fold concentration over the antibody). The anti-proliferative effect of anti-Wnt-1 antibody on Huh7 and Hep40 cells were blocked by pre-treatment with the blocking peptide (Fig. 2C), suggesting that the anti-Wnt- 1 antibody can bind specifically to the native form of the Wnt-1 protein in these cells, and that the observed anti-proliferative effect is mediated by inhibition of Wnt-1 protein functions by the anti-Wnt-1 antibody.

Using the TUNEL assay, induction of apoptosis was observed at an effective concentration of anti-Wnt-1 antibody in Huh7 (Fig. 2D) and Hep40 cells (data not shown). Most of the dead cells were stained as apoptotic cells when treated with $10 \mu \mathrm{g} / \mathrm{ml}$ of the anti-Wnt-1 antibody for 72 hrs (Fig. 2D). Overnight pretreatment with the Wnt-1 specific blocking peptide (20-fold over antibody) markedly reduced the number of apoptotic cells after treatment with anti-Wnt-1 antibody (Fig. 2D). Our data suggest that cell apoptosis was specifically induced by the anti-Wnt- 1 antibody in Huh7 and Hep40 cells.

\section{Anti-Wnt-I antibody inhibits Wnt/ $\beta$-catenin signaling and suppresses the expression of downstream oncoproteins}

To determine if the effects of anti-Wnt- 1 antibody on Huh7 and Hep40 cells were related to inhibition of Wnt/ $\beta$-catenin signaling, we used the Tcf4 transcriptional 
A

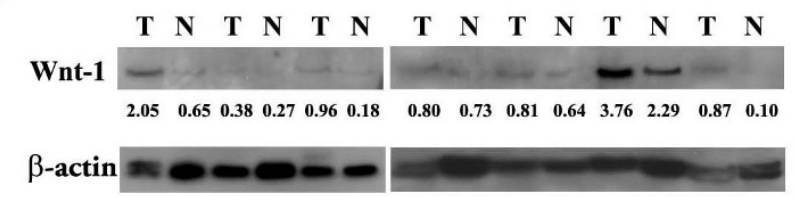

B

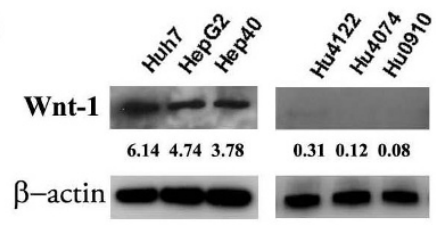

Figure I

Expression of Wnt-I protein in human HCC tumors and cell lines. A). Western blot detection of Wnt-I expression in human HCC tumor tissues (T) and the corresponding adjacent non-tumor liver tissues (N). B). Western blot detection of Wnt-I expression in HCC cell lines (HepG2, Huh7, and Hep40), and normal hepatocytes from three donors (Hu0910, Hu4I22, Hu4074). The immunoblots were quantified by densitometry and the intensities normalized with those of $\beta$-actin and given beneath each band.

reporter (TOP/FOP FLASH) assay to detect $\beta$-catenin/Tcf4 transcriptional activity in these cell lines after $48 \mathrm{hr}$ treatment with the antibody $(2 \mu \mathrm{g} / \mathrm{ml})$. The anti-Wnt- 1 antibody dose-dependently decreased $\beta$-catenin/Tcf4 transcriptional activity (Fig. 3A), and also reduced the accumulation of $\beta$-catenin in the nuclei of Huh7 and Hep40 cells (Fig. 3B). No effects on $\beta$-catenin/Tcf4 transcriptional activity or $\beta$-catenin accumulation were observed in HepG2 cells (data not shown). Control IgG had no effect on transcriptional activity or nuclear $\beta$-catenin levels. Consistent with these observations, the endogenous levels of $\beta$-catenin/Tcf4 regulated proteins (cMyc, cyclin D1, and survivin) were reduced after $48 \mathrm{hr}$ treatment with the anti-Wnt-1 antibody $(2 \mu \mathrm{g} / \mathrm{ml})$, but not after treatment with control IgG (Fig. 3C). These three proteins are commonly known to be over-expressed in HCC tissues [7-9], and our results indicate that their expression is regulated by Wnt-1-mediated $\beta$-catenin/Tcf4 signaling.

\section{Anti-Wnt-I antibody inhibits growth of HCC xenografts in nude mice}

We next studied the in vivo effects of the anti-Wnt- 1 antibody on tumor growth in a HCC xenograft model in nude mice. Huh7 cells were injected subcutaneously into nude mice to initiate tumor formation. When established xenografts were palpable (approximately after 14 days), mice were intratumorally injected with the anti-Wnt-1 antibody (50 $\mu \mathrm{g} / \mathrm{kg}$ ), and PBS as control ( $\mathrm{n}=5$ in each group) once weekly. Compared with PBS control, the anti-Wnt-1 antibody effectively inhibited tumor growth in vivo (ANOVA, $\mathrm{P}<0.05$, compared with $\mathrm{PBS}$ control at the beginning of the third week) (Fig. 4A). Tumor tissues were harvested after sacrificing the mice at the end of the treatment period, and were analyzed via TUNEL staining. Apoptotic cells were detected in tumors treated with the anti-Wnt-1 antibody, but not in the control group (Fig. 4B). When immunostained with anti-c-Myc, cyclin D1, and survivin antibodies, tumor tissues that had been treated with anti-Wnt-1 antibody showed reduced c-Myc, cyclin D1, and survivin expressions (Fig. 4C and 4D). These results are consistent with our in vitro observations that the antibody inhibited $\beta$-catenin/Tcf4 mediated transcriptional activity.

\section{Discussion}

The Wnt gene family encodes at least 19 secreted factors involved in cell growth, differentiation, embryogenesis and oncogenesis [21]. The expression of the Wnt-1 ligand in mammalian cells results in the accumulation of steadystate levels of cytosolic and nuclear $\beta$-catenin [22], which contributes to the development of many types of cancers [6]. Recently, several Wnt proteins, including Wnt-1, have been shown to be over-expressed in HCC tumor compared with the corresponding non-tumor tissue from hepatitis B and C-infected patients [16]. Moreover, in vitro models have been used to study how the over-expression of Wnt-1 is involved in HCV-induced Huh-7 cell proliferation and HBV X protein-induced $\beta$-catenin/Tcf4 transcription activation $[19,23]$. Consistent with these recent findings, we have shown that Wnt-1 protein is overexpressed in HCC tissues and cell lines, but not in adjacent non-tumor liver tissues or cultured normal hepatocytes. Our in vitro and in vivo data further support the use of an anti-Wnt-1 antibody as a new treatment option for HCC, since it blocks Wnt-1 mediated $\beta$-catenin/Tcf4 transcription, which in turn leads to reduced proliferation, enhanced apoptosis, and down-regulation of important downstream target oncoproteins in HCC.

Wnt-1-mediated $\beta$-catenin/Tcf4 transcription is an important cellular survival pathway that promotes cell proliferation, cell cycle progression, and cellular transformation [24]. Because Wnt proteins are indispensible for cancer cell growth and survival, we studied the potential antitumor effect of anti-Wnt-1 antibody in HCC cells. Compared to the control goat IgG, anti-Wnt-1 antibody decreased proliferation and induced apoptosis in Huh7 and Hep40 cell lines over-expressing Wnt-1 protein (and with wild type $\beta$-catenin). These effects were blocked by pre-treatment with the Wnt-1 blocking peptide, demonstrating that they were mediated by specific binding of the anti-Wnt- 1 antibody to the native form of Wnt-1 protein 
A

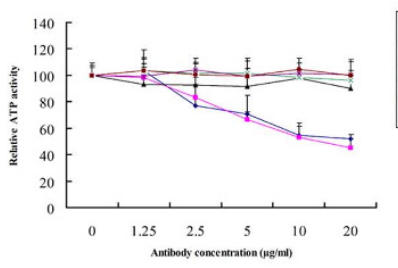

C
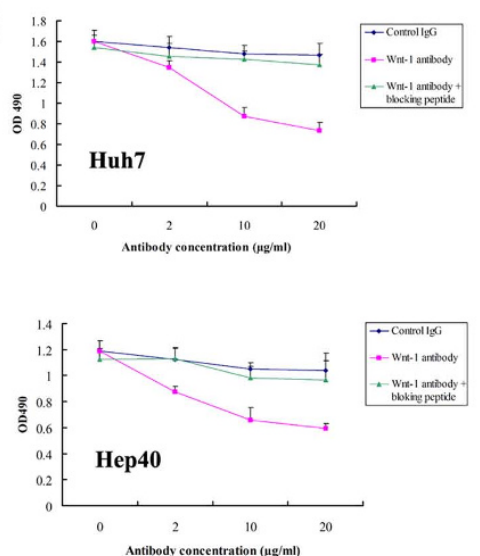

D
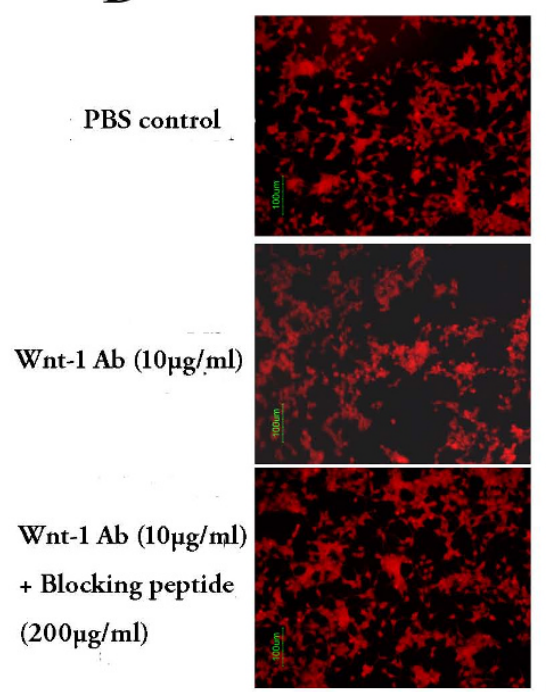

B

Huh7

Wnt-1 Ab

( $2 \mu \mathrm{g} / \mathrm{ml})$
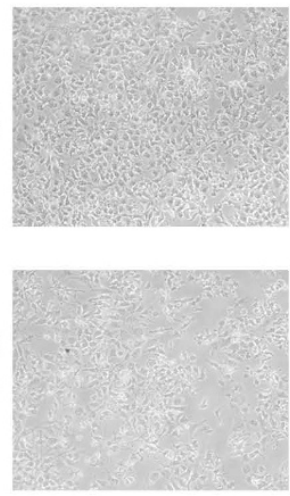

Wnt-1 Ab

$(10 \mu \mathrm{g} / \mathrm{ml})$

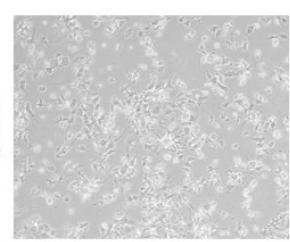

Hu0910
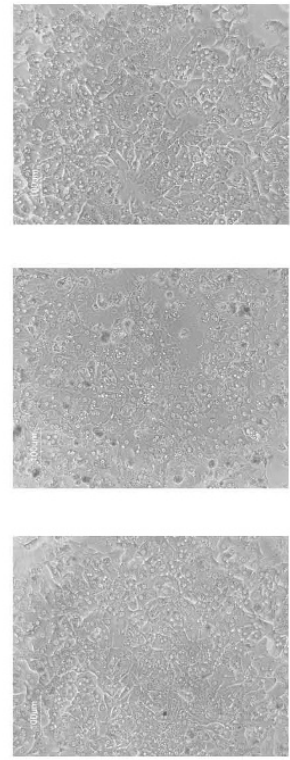

\section{TUNEL}
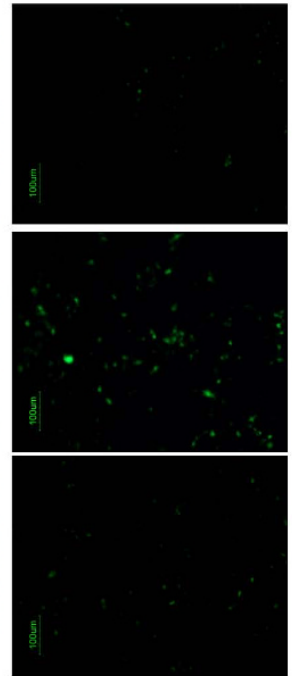

\section{Overlay}
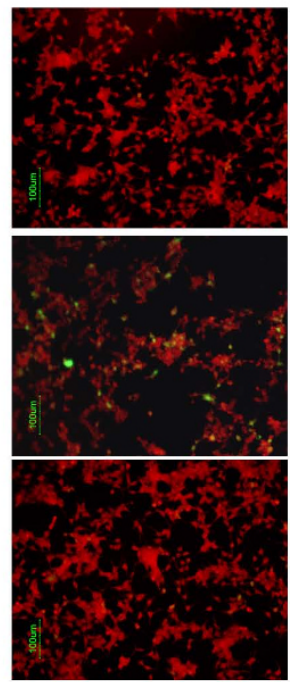

\section{Figure 2}

In vitro anti-proliferative and apoptotic effects of anti-Wnt-I antibody on human HCC cell lines. A). Cell viability assays based on cellular ATP content were used to determine the effect of anti-Wnt-I antibody on three human HCC cell lines and normal hepatocytes from three donors following $72 \mathrm{hr}$ of antibody treatment. Relative ATP activity is proportional to the number of viable cells. Three independent experiments were done, each in triplicates. B). Phase-contrast microscopic examination of the effect of different concentrations of anti-Wnt-I antibody on HCC cell line Huh7 and normal hepatocytes Hu09I0. C). Pre-treatment with Wnt-I specific blocking peptide abolished the anti-proliferative effect of anti-Wnt-I antibody in Huh7 and Hep40 cells. Results are presented as mean \pm SD (error bars). D). Anti-Wnt-I antibody induced apoptosis in Huh7 cells. Huh7 cells were treated with anti-Wnt-I antibody $(10 \mu \mathrm{g} / \mathrm{ml})$ with or without blocking peptide pre-treatment. After $72 \mathrm{hr}$ incubation, cells were washed, fixed, and stained with TUNEL and PI as described under Materials and Methods to detect for apoptotic cells. Fluorescence labeling was visualized and photographed at $100 \times$ magnification. 
in these cells. However, the anti-Wnt-1 antibody had no effect on HepG2 cells (with high expression of Wnt-1 protein, but harbors both wild type and truncated $\beta$-catenin) $[25]$, and normal hepatocytes from three different donors (with undetectable Wnt-1 expression). Truncation of $\beta$ catenin in HepG2 cells is caused by a large gene deletion (loss of amino acids 20-140) involving loss of the GSK-3 $\beta$ regulatory site, which leads to failure of the protein to be phosphorylated by GSK3 $\beta$. Thus, $\beta$-catenin constitutively accumulates in the nucleus of HepG2 cells and may escape regulation by the anti-Wnt-1 antibody acting upstream. Similar results were observed by Shih et al. [20], who found that the restoration of secreted frizzled-related proteins (SFRPs; extracellular signaling glycoproteins that antagonize Wnt signaling) attenuated Wnt signaling in Huh6 cells (with a $\beta$-catenin point mutation), but not in HepG2 cells with truncated $\beta$-catenin. However, as the incidence of similar $\beta$-catenin truncation is low in human HCC (only 1 out of 26 HCC patients had $\beta$-catenin truncation) [25], the anti-Wnt-1 antibody has potential wide applicability in the majority of HCC patients.

Activation of $\beta$-catenin/Tcf4 transcription by Wnt-1 has been reported to be responsible for Wnt-1-mediated cell survival [24]. Longo et al. [26] also demonstrated that Wnt-1 caused 3T3-L1 cells to resist apoptosis in response to serum deprivation through inhibition of GSK-3 $\beta$ activity and stabilization of $\beta$-catenin. Conversely, blockade of Wnt-1 signaling using Wnt-1 antibodies have been reported to induce apoptosis in a variety of human cancer cell lines, including non small cell lung cancer, breast cancer, colorectal cancer mesothelioma, and sarcoma $[27,28]$. Treatment with antibodies against Wnt-1 and Wnt-10b also inhibited proliferation and induced apoptosis in head and neck squamous cell carcinoma (HNSCC) cells [29]. Consistently, we observed that antiWnt- 1 antibody inhibited $\beta$-catenin/Tcf4 transcriptional activity as measured using the TOPFLASH and FOPFLASH reporter assay, and also led to accumulation of $\beta$-catenin in the nuclei of Huh7 and Hep40 cells. This implies that anti-Wnt-1 antibody acts via the canonical Wnt signaling cascade to induce apoptosis in both cell lines.

The canonical Wnt signaling pathway, via the $\beta$-catenin/ Tcf4 complex, regulates the expression of multiple oncoproteins, including c-Myc, cyclin D1, and survivin in HCC [7-9]. In the Huh7 and Hep40 cells in vitro, anti-Wnt-1 antibody markedly reduced the expression of c-Myc, cyclin D1, and survivin, consistent with its ability to inhibit $\beta$-catenin/Tcf4 transcriptional activity. One of the most common oncoproteins associated with the pathogenesis of HCC is c-Myc [8]; its elevated expression in mice models was found to initiate and promote liver tumor growth $[30,31]$. The deletion of c-Myc alone in a mouse liver tumor model efficiently suppressed tumor growth in vivo
[32]. Cyclin D1 was reported to be significantly elevated in HCC compared with surrounding cirrhotic tissues [9]. In HCC cells, cyclin D1-related kinase activity was accompanied by up-regulation of Cdk4 activity, and phosphorylated and activated $\mathrm{pRB}$, which promote $\mathrm{G} 1$ to $\mathrm{S}$ phase transition [9]. Additionally, the over-expression of survivin promotes proliferation in HCC by initiating cell cycle entry (a decrease in the G0/G1 phase and an increase in the S phase) [7]. Its inhibition led to cell cycle arrest, an effect which can augment the sensitivity of HCC tumor cells to cytotoxic drugs [33]. These three oncoproteins (cMyc, cyclin D1, and survivin) have important functional roles in the development of HCC, and the ability to regulate them simultaneously offers a powerful way to intervene with HCC progression.

\section{Conclusion}

In conclusion, our data suggest that targeting Wnt- 1 mediated $\mathrm{Wnt} / \beta$-catenin signaling (which is frequently activated in HCC) may be a feasible and novel therapeutic option. The specific and effective blockade of this signaling pathway using an anti-Wnt-1 antibody inhibited HCC cell proliferation and induced apoptosis in vitro. Correspondingly, suppression of HCC tumor xenograft growth and apoptosis were also observed in vivo. The ability of the anti-Wnt-1 antibody to down-regulate the expression of downstream targets of Wnt $/ \beta$-catenin signaling, including c-Myc, cyclin D1, and survivin, suggest that a broad spectrum of cellular mechanisms can be triggered in concert to halt HCC tumor growth. Lastly, since Wnt-1 is often deregulated in HCC with underlying HBV or HCV (the main risks factors of HCC), we propose that interference with Wnt-1 mediated signaling offers a potent and selective therapeutic strategy for the clinical management of a substantial proportion of HCC patients with Wnt-1 overexpression.

\section{Material and methods}

Tissue samples and cell lines

Paired (HCC and adjacent non-tumor liver) tissues were obtained from seven patients who underwent liver resection for HCC at Stanford Hospital, Stanford University, California. This study was approved by the Institutional Review Board for the use of human subjects in medical research, and informed consent was obtained from patients prior to liver resection. Ages ranged from 44 to 73 years. All patients were men with HBV-related HCC.

Human hepatoma cell lines, HepG2, Hep40, and Huh7 were maintained in Dulbecco's Modified Eagle's Medium (DMEM) supplemented with $10 \%$ fetal bovine serum (FBS), $100 \mu \mathrm{g} / \mathrm{mL}$ penicillin and $100 \mu \mathrm{g} / \mathrm{mL}$ streptomycin. All media and supplements were from Invitrogen (Carlsbad, CA). Cells were maintained at $37^{\circ} \mathrm{C}$ in a humidified atmosphere with $5 \% \mathrm{CO}_{2}$. 
A
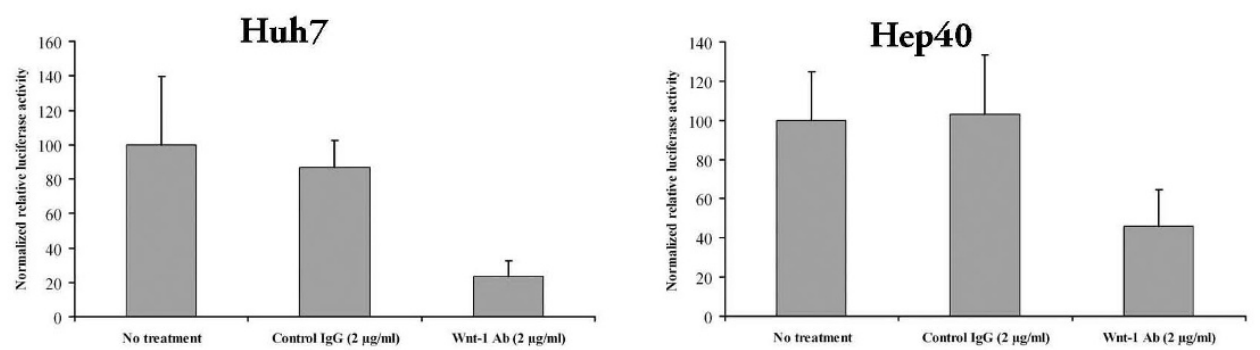

B

Huh7

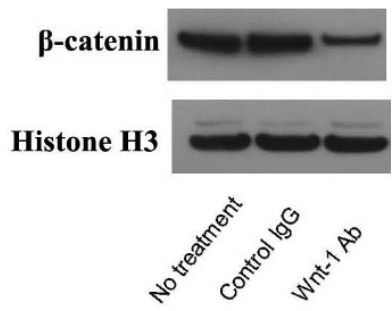

C

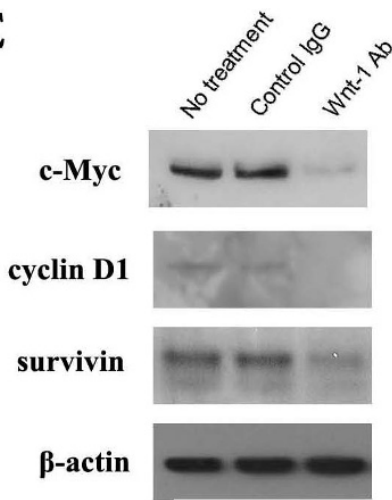

Huh7

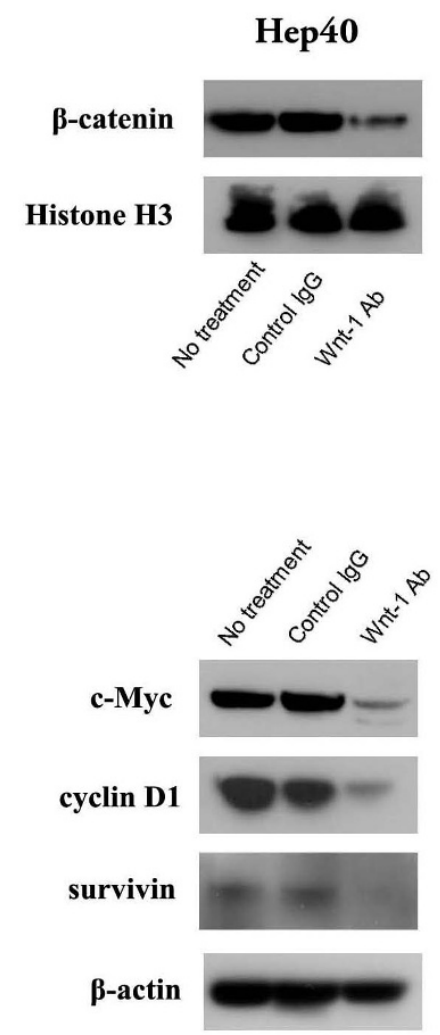

Hep40

Figure 3

Anti-Wnt-I antibody inhibited $\beta$-catenin/Tcf4 transcriptional activity. A). Tcf4 reporter assay of Tcf-dependent transcriptional activity in Huh7 and Hep40 cell lines. Huh7 and Hep40 cells were co-transfected with plasmid encoding $\beta$-galactosidase (a control for transfection efficiency) and either the PTOPFLASH or pFOPFLASH reporters. Cells were incubated with anti-Wnt-I antibody or control lgG $(2 \mu \mathrm{g} / \mathrm{ml})$ and harvested after $48 \mathrm{hr}$ to measure luciferase and $\beta$-galactosidase activities. Reporter gene activation is expressed in terms of relative light units (RLU) detected in PTOPFLASH or pFOPFLASH transfected cells and normalized for $\beta$-galactosidase activity. The results are expressed as mean \pm SD (error bars). Experiments were performed in triplicates; $\mathrm{P}<0.05$. B). Anti-Wnt-I antibody decreased nuclear $\beta$-catenin accumulation in Huh7 and Hep40 cells. Histone 3 was used as the loading control. C). The effect of anti-Wnt-I antibody on the expression of $\beta$-catenin/Tcf 4 target genes c-Myc, cyclin DI, and survivin. Huh7 and Hep40 cells were incubated for $48 \mathrm{hr}$ with anti-Wnt-I antibody $(2 \mu \mathrm{g} / \mathrm{ml})$ and c-Myc, cyclin DI, survivin and $\beta$-actin (loading control) levels were determined by Western blotting using specific antibodies. 


\section{Anti-Wnt-I antibody and blocking peptide}

The anti-Wnt-1 goat polyclonal antibody, the corresponding control goat IgG, and the Wnt-1 specific blocking peptide were from Santa Cruz Biotechnology (Santa Cruz, CA). Antibodies were concentrated using Microcon-30 ultrafugation devices (Millipore Corporation, Bedford, MA) before being added to cells. The blocking peptide was purified by dialysis using a Slide-A-Lyzer Dialysis Cassette with a 2,000 MWCO (Promega, Madison, WI). For blocking experiments, blocking peptide was pre-incubated with cells overnight, at 20-fold concentration over the antiWnt-1 antibody.

\section{Primary culture of hepatocytes}

Cryopreserved human hepatocytes, collagen hand-coated 96-well plates, CHRM Thawing Medium, Cell Plating Medium, and Cell Maintenance Medium were received from CellzDirect/Invitrogen (Durham, NC). Characteristics of the three hepatocyte lots are shown in Table 1. Cryopreserved human hepatocytes were thawed based upon CellzDirect's standard method: hepatocytes were thawed at $37^{\circ} \mathrm{C}$, then poured into pre-warmed $37^{\circ} \mathrm{C}$ CHRM Thawing Medium at a ratio of one vial (approximately 5 million cells) $/ 50 \mathrm{ml}$ in a conical tube. The cells were then centrifuged at $100 \mathrm{~g}$ for $10 \mathrm{~min}$ and resuspended to $0.75 \times$ $10^{6}$ cells/mL in Plating Medium. Cell viability was determined by trypan blue exclusion. Hepatocytes were then plated in collagen-coated 96-well plates at a density of $3 \times$ $10^{4}$ cells/well in a volume of $100 \mu \mathrm{l} /$ well. After $5 \mathrm{~h}$ of incubation at $37^{\circ} \mathrm{C}$, Plating Media was replaced with serumfree Maintenance Media at $100 \mu \mathrm{l} /$ well, and incubated overnight for cytotoxicity assay as described below.

\section{Cell viability and proliferation assays}

Hepatoma cells were seeded in 96-well plates at $3 \times 10^{3}$ cells/well, and incubated overnight at $37^{\circ} \mathrm{C}$ prior to addition of anti-Wnt-1 antibody. Anti-Wnt-1 antibody and control IgG were added at desired final concentrations (range from $0-20 \mu \mathrm{g} / \mathrm{ml}$ ), and further incubated for $72 \mathrm{~h}$ before cell viability and proliferation were assessed using CellTiter-Glo Luminescent Cell Viability Assay (Promega, Madison, WI) or .CellTiter $96^{\circledR}$ AQueous One Solution Cell Proliferation Assay (Promega, Madison, WI) respectively, according to the manufacturer's instructions. Briefly, for the .CellTiter-Glo assay, the assay regents (a combination of detergent and luciferase-based enzyme) were directly added to cultured cells, resulting in cell lysis and the production of a bioluminescent signal proportional to the amount of ATP present. Luciferase activity was measured on a luminometer (Berthold LB-96V) and values were normalized to the ATP activity and compared with their respective PBS control value, which was set at 100. Three independent experiments were done, each in triplicates. For proliferation assay, optical density (OD) was read at $490 \mathrm{~nm}$ using a SAFIRE microplate reader
(TECAN, Research Triangle Park). The background value (mean OD values from wells with only the AQueous One Solution) was subtracted from all data. Three independent experiments were done, each in triplicates.

\section{Luciferase reporter gene assay}

$\beta$-catenin/Tcf4 transcriptional reporter gene assays were performed using TCF/Luc reporter constructs, wild type pTOPFLASH, and mutant pFOPFLASH, which were generously provided by B Vogelstein (John Hopkins Oncology Center, Baltimore, MD, USA) [34]. Cells were seeded at 3 $\times 10^{4}$ cells/well into 24 -well plates and incubated for $24 \mathrm{hr}$ prior to transfection with wild type pTOPFLASH or mutant pFOPFLASH $(0.7 \mu \mathrm{g})$ using Lipofectamine 2000 (Invitrogen, Carslbad, CA) according to the manufacturer's instructions. The $\beta$-galactosidase ( $\beta$-gal) expression vector $(0.1 \mu \mathrm{g})$ was added to each transfection system to normalize the transfection efficiency. After $4 \mathrm{hr}$, medium containing transfection regent was replaced with new culture medium containing the anti-Wnt-1 antibody or control IgG $(2 \mu \mathrm{g} / \mathrm{ml})$. After $48 \mathrm{hr}$, cells were lysed in $100 \mu \mathrm{l}$ of lysis buffer, and $20 \mu$ aliquots were assayed for luciferase activity using the Promega Luciferase assay system or for $\beta$-gal activity using the Promega $\beta$-gal assay system. Relative light units (RLU) were measured and normalized for transfection efficiency using $\beta$-gal activity. Final RLU representing Tcf4 transcriptional activity were calculated by subtracting normalized levels obtained with pFOPFLASH from those obtained with pTOPFLASH.

\section{Apoptosis Analysis}

TUNEL (Terminal dUTP nick-end labeling) assays (Promega, Madison, WI) were performed according to the manufacturer's protocol. Briefly, Huh7 or Hep40 cells were seeded in 8-chamber BD tissue culture slides (BD Bioscience Labware, Bedmord, MA) at 10\% confluency. Control IgG or anti-Wnt-1 antibody was added to the medium at final concentration of $10 \mu \mathrm{g} / \mathrm{ml}$ each. After 72 hr incubation, cells were washed twice with PBS, and then fixed in 4\% paraformaldehyde for $25 \mathrm{~min}$. Fixed cells were washed twice in PBS with $0.1 \%$ Triton X-100, and then incubated with TUNEL reaction mixture for $60 \mathrm{~min}$ at $37^{\circ} \mathrm{C}$. After washing with $2 \mathrm{xSSC}$, slides were immersed in PBS with $1 \mu \mathrm{g} / \mathrm{ml}$ Propidium Iodide (PI) for $5 \mathrm{~min}$ in the dark and then washed with PBS. Fluorescence labeling was visualized and photographed $(100 \times$ magnification) with a fluorescence microscope (Nikon Eclipse 80i, Nikon Corporation, Tokyo, Japan) and with a digital camera (Nikon DXM1200f, Nikon Corporation, Tokyo, Japan). For TUNEL staining of the tumor xenografts, $4-\mu \mathrm{m}$ tissue sections of tumor xenografts from in vivo experiments were stained using the ApopTag Peroxidase in Situ Oligo Ligation Apoptosis Detection Kit (Chemicon International, Temecula, CA) according to the manufacturer's protocol. 
A

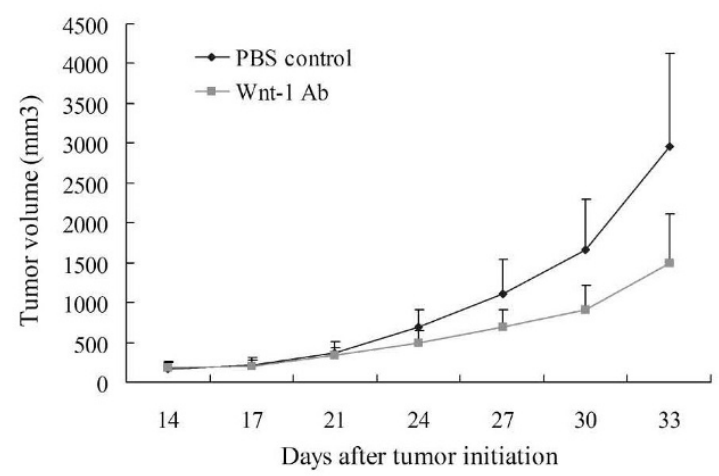

B

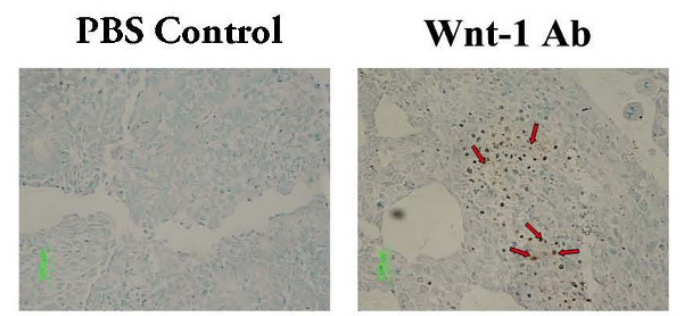

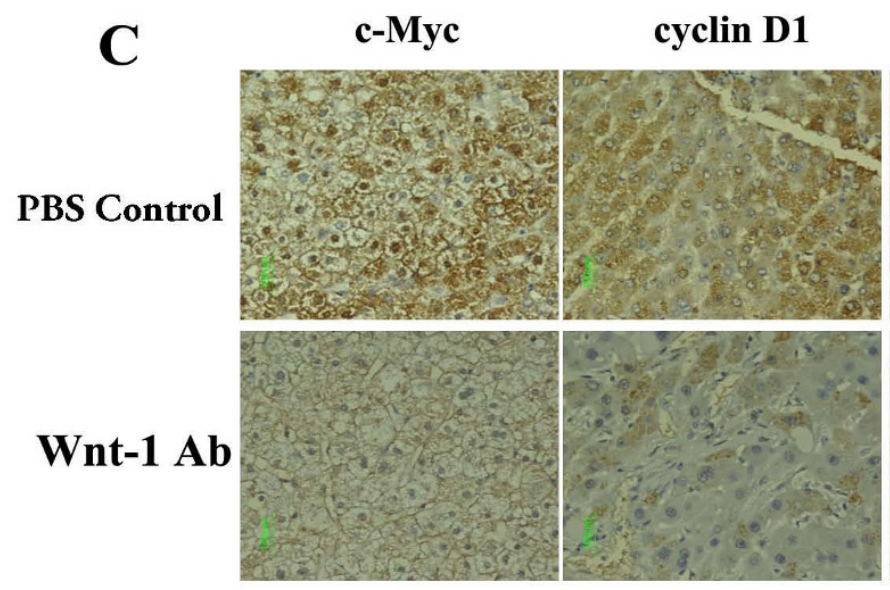

Survivin
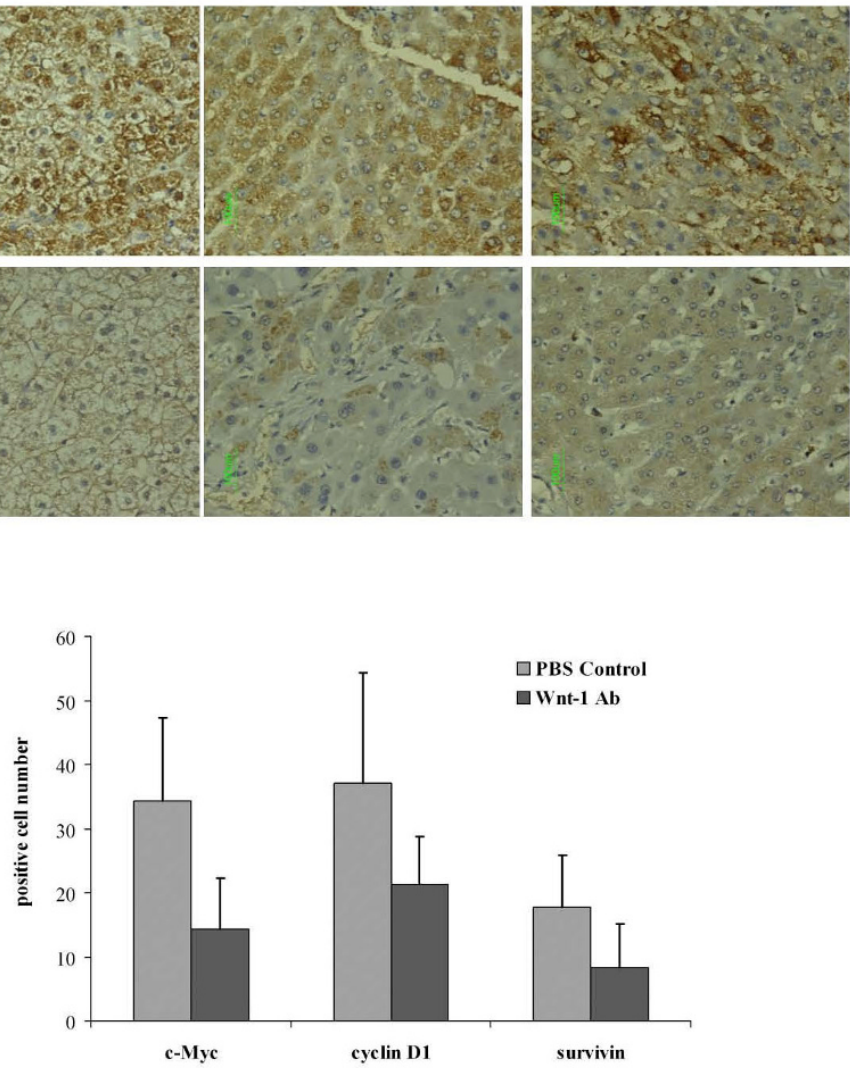

Figure 4

Anti-Wnt-I antibody suppressed tumor xenograft growth in vivo. A). Nude mice bearing Huh7 tumor xenografts were treated with anti-Wnt-I antibody (dose: $50 \mu \mathrm{g} / \mathrm{kg}$; once a week), or with PBS as a control ( $\mathrm{n}=5$ in each group). Significant differences in the tumor volumes between anti-Wnt-I antibody-treated and PBS control groups were observed at the beginning of the third week after initiation of treatment $(P<0.05)$. B). TUNEL staining of the xenograft specimens removed from controls and mice treated with anti-Wnt-I antibody (200x magnification). Red arrows indicate the positively stained apoptotic cells. C). Xenograft specimens removed from controls and mice treated with anti-Wnt-I antibody were immunostained to detect expression of c-Myc, cyclin DI, and survivin (400× magnification). The number of positively stained cells were counted from three randomly selected areas and the values represent mean \pm SD (error bars). 


\section{Western blotting and antibodies}

Huh7 or Hep40 cells were seeded at $50 \%$ confluency in 6well plates and incubated at $37^{\circ} \mathrm{C}$ overnight. Cells were then treated with PBS, control IgG, or anti-Wnt-1 antibody $(2 \mu \mathrm{g} / \mathrm{ml})$ for $48 \mathrm{hr}$. Cell monolayers were washed twice with PBS and then lysed in RIPA extraction buffer. For nuclear $\beta$-catenin immunodetection, nuclear extracts were prepared with a NE-PER Nuclear and Cytoplasmic Extraction Kit (Pierce, Rockford, IL). Equal amounts of protein $(20 \mu \mathrm{g})$ were resolved by SDS-PAGE and Western blots were performed by using the primary antibodies to c-Myc (1:500, Cat. 551101, BD Pharmingen, San Diego, CA), cyclin D1 (1:1000, Cat. ab6152, Abcam, Cambridge, MA) , survivin (1:1000, Cat. NB500-201H, Novas Biologicals, Littleton, CO), $\beta$-catenin (1:500; Cat. SC-7963, Santa Cruz Biotechnology, Santa Cruz, CA), Histone H3 (1:10000, Cat. Ab21054, Abcam, Cambridge, MA) or $\beta$ actin (1:10000, Cat.A3854, Sigma-Aldrich, MO). Secondary antibodies (anti-mouse, Cat.SC-2005, and anti-rabbit, Cat.SC-2004) conjugated with horseradish peroxidase were obtained from Santa Cruz Biotechnology (Santa Cruz, CA). Western blots were analyzed by ImageJ software, and signal intensities normalized to $\beta$-actin.

\section{Xenografts in Nude Mice}

Nude mice (ATHYMIC NU/NU; Harlan Sprague-Dawley, Indianapolis, IN) at age 4-6 weeks with a body weight of 18 to $25 \mathrm{~g}$ were used for the experiments. Mice were injected subcutaneously at the dorsal region with $5 \times 10^{6} /$ $150 \mu \mathrm{l}$ viable Huh7 cells. After two weeks, when tumors reached approximately $0.4-0.5 \mathrm{~cm}$ in diameter, mice were randomized into groups $(n=5)$ to be intratumorally injected with $100 \mu \mathrm{l}$ of PBS or anti-Wnt-1 antibody at the dose of $50 \mu \mathrm{g} / \mathrm{kg}$ once a week. Tumor size was measured with digital calipers every three days and was calculated using the formula $\pi / 6 \times$ larger diameter $\times$ [smaller diameter $]^{2}$. Mice were sacrificed at the end of the treatment period, and xenografts harvested.

\section{Immunohistochemical Analysis}

Immunoperoxidase stain of tumor xenografts was performed on acetone-fixed $4-\mu \mathrm{m}$ tissue sections. Briefly, sections were incubated with monoclonal mouse antihuman c-Myc (1:200, Cat. 551101, BD Pharmingen, San Diego, CA), cyclin D1 (1:250, Cat. ab6152, Abcam, Cam-

Table I: Characteristics of tested normal hepatocytes

\begin{tabular}{lllll}
\hline Lot & Age (y) & Gender & Race & Cell viability \\
\hline Hu4I22 & 19 & Male & Caucasian & $92 \%$ \\
\hline Hu0910 & 56 & Female & Caucasian & $96 \%$ \\
\hline Hu4074 & 47 & Male & Caucasian & $87 \%$
\end{tabular}

bridge, MA), or survivin (1:500, Cat. NB500-201H, Novas Biologicals, Littleton, CO) and then washed with PBS. Subsequent procedures were performed using Dakocytomation Envision System-HRP mouse system (DakoCytomation Inc, CA, USA) according to the manufacturer's protocol. We observed c-Myc staining in the cytoplasm and nuclei, and cyclin D1 and survivin staining in the cyptoplasm, consistent with other reports in HCC [35-37]. Therefore, for quantification, 100 cells at 3 randomly selected areas were assessed, and the number of cells that stained positively for c-Myc, cyclin D1, or survivin were counted.

\section{Statistical analysis}

Statistical analysis was performed by one-way ANOVA and independent-sample T-test using the computer SPSS software. In all assays, the probability value $(\mathrm{P})$ of $<0.05$ was considered statistically significant.

\section{Abbreviations}

HCC: Hepatocellular carcinoma; HBV: hepatitis B virus; Tcf4: T-cell factor 4; TUNEL: Terminal dUTP nick-end labeling; PI: propidium iodide

\section{Competing interests}

The authors declare that they have no competing interests.

\section{Authors' contributions}

WW contributed to the major part of experimental work, interpreted the results, performed the statistics and drafted the manuscript. MC conceived the study, participated in its design and data analysis, and contributed with scientific discussion and manuscript preparation. SG contributed the normal hepatocytes and provided training and advice on culturing the hepatocytes. SKS is the principal investigator, responsible for conception of the project, designing the experiments, and approving the final manuscript. All authors read and approved the final manuscript.

\section{Acknowledgements}

This work is supported by grants to the Asian Liver Center at Stanford University from the H. M. Lui and C. J. Huang Foundations.

\section{References}

I. Parkin DM, Pisani P, Ferlay J: Estimates of the worldwide incidence of 25 major cancers in 1990. Int J Cancer 1999, 80:827-841.

2. Llovet JM, Bustamante J, Castells A, Vilana R, Ayuso Mdel C, Sala M, Bru C, Rodes J, Bruix J: Natural history of untreated nonsurgical hepatocellular carcinoma: rationale for the design and evaluation of therapeutic trials. Hepatology 1999, 29:62-67.

3. Llovet JM, Burroughs A, Bruix J: Hepatocellular carcinoma. Lancet 2003, 362:1907-1917.

4. Liu JH, Chen PW, Asch SM, Busuttil RW, Ko CY: Surgery for hepatocellular carcinoma: does it improve survival? Ann Surg Oncol 2004, I I:298-303.

5. Peifer $M$, Polakis $P$ : Wnt signaling in oncogenesis and embryogenesis--a look outside the nucleus. Science 2000, 287:1606-1609. 
6. Polakis P: Wnt signaling and cancer. Genes Dev 2000, I4:|837-|85|.

7. Ito T, Shiraki K, Sugimoto K, Yamanaka T, Fujikawa K, Ito M, Takase K, Moriyama M, Kawano H, Hayashida M, et al.: Survivin promotes cell proliferation in human hepatocellular carcinoma. Hepatology 2000, 31: 1080-1085.

8. Liu YC, Chen CJ, Wu HS, Chan DC, Yu JC, Yang AH, Cheng YL, Lee $\mathrm{SC}$, Harn HJ: Telomerase and c-myc expression in hepatocellular carcinomas. Eur J Surg Oncol 2004, 30:384-390.

9. Masaki T, Shiratori Y, Rengifo W, Igarashi K, Yamagata M, Kurokohchi K, Uchida N, Miyauchi Y, Yoshiji H, Watanabe S, et al:: Cyclins and cyclin-dependent kinases: comparative study of hepatocellular carcinoma versus cirrhosis. Hepatology 2003, 37:534-543.

10. Endo K, Ueda T, Ueyama J, Ohta T, Terada T: Immunoreactive Ecadherin, alpha-catenin, beta-catenin, and gamma-catenin proteins in hepatocellular carcinoma: relationships with tumor grade, clinicopathologic parameters, and patients' survival. Hum Pathol 2000, 31:558-565.

II. Inagawa S, Itabashi M, Adachi S, Kawamoto T, Hori M, Shimazaki J, Yoshimi F, Fukao K: Expression and prognostic roles of betacatenin in hepatocellular carcinoma: correlation with tumor progression and postoperative survival. Clin Cancer Res 2002, 8:450-456.

12. Merle P, de la Monte S, Kim M, Herrmann M, Tanaka S, Bussche A Von Dem, Kew MC, Trepo C, Wands JR: Functional consequences of frizzled-7 receptor overexpression in human hepatocellular carcinoma. Gastroenterology 2004, 127:1 I 10-1122.

13. Merle P, Kim M, Herrmann M, Gupte A, Lefrancois L, Califano S, Trepo C, Tanaka S, Vitvitski L, de la Monte S, Wands JR: Oncogenic role of the frizzled-7/beta-catenin pathway in hepatocellular carcinoma. J Hepatol 2005, 43:854-862.

14. Huang CL, Liu D, Ishikawa S, Nakashima T, Nakashima N, Yokomise $\mathrm{H}$, Kadota K, Ueno M: Wnt I overexpression promotes tumour progression in non-small cell lung cancer. Eur J Cancer 2008, 44:2680-2688.

15. Katoh M: Expression and regulation of WNTI in human cancer: up-regulation of WNT I by beta-estradiol in MCF-7 cells. Int J Oncol 2003, 22:209-2I 2.

16. Lee TH, Tai DI, Cheng C], Sun CS, Lin CY, Sheu MJ, Lee WP, Peng $\mathrm{CY}$, Wang AH, Tsai SL: Enhanced nuclear factor-kappa B-associated Wnt-I expression in hepatitis B- and C-related hepatocarcinogenesis: identification by functional proteomics. J Biomed Sci 2006, 13:27-39.

17. Calvisi DF, Conner EA, Ladu S, Lemmer ER, Factor VM, Thorgeirsson SS: Activation of the canonical Wnt/beta-catenin pathway confers growth advantages in c-Myc/E2FI transgenic mouse model of liver cancer. J Hepatol 2005, 42:842-849.

18. Lee HH, Uen YH, Tian YF, Sun CS, Sheu MJ, Kuo HT, Koay LB, Lin $C Y$, Tzeng CC, Cheng CJ, et al.: Wnt-I protein as a prognostic biomarker for hepatitis B-related and hepatitis C-related hepatocellular carcinoma after surgery. Cancer Epidemiol Biomarkers Prev 2009, 18:1562-1569.

19. Cha MY, Kim CM, Park YM, Ryu WS: Hepatitis B virus $\mathbf{X}$ protein is essential for the activation of $\mathrm{Wnt} / \mathrm{beta}$-catenin signaling in hepatoma cells. Hepatology 2004, 39:1683-1693.

20. Shih YL, Hsieh CB, Lai HC, Yan MD, Hsieh TY, Chao YC, Lin YW: SFRPI suppressed hepatoma cells growth through Wnt canonical signaling pathway. Int / Cancer 2007, I 21:1028- 1035.

21. Nusse R, Varmus HE: Wnt genes. Cell 1992, 69:1073-1087.

22. Papkoff J, Rubinfeld B, Schryver B, Polakis P: Wnt-I regulates free pools of catenins and stabilizes APC-catenin complexes. Mol Cell Biol 1996, 16:2128-2134.

23. Fukutomi T, Zhou Y, Kawai S, Eguchi H, Wands JR, Li J: Hepatitis C virus core protein stimulates hepatocyte growth: correlation with upregulation of wnt-I expression. Hepatology 2005, 41:1096-I105

24. Chen S, Guttridge DC, You Z, Zhang Z, Fribley A, Mayo MW, Kitajewski J, Wang CY: Wnt-I signaling inhibits apoptosis by activating beta-catenin/T cell factor-mediated transcription. J Cell Biol 200I, I 52:87-96.

25. de La Coste A, Romagnolo B, Billuart P, Renard CA, Buendia MA, Soubrane O, Fabre M, Chelly J, Beldjord C, Kahn A, Perret C: Somatic mutations of the beta-catenin gene are frequent in mouse and human hepatocellular carcinomas. Proc Natl Acad Sci USA 1998, 95:8847-885I.
26. Longo KA, Kennell JA, Ochocinska MJ, Ross SE, Wright WS, MacDougald OA: Wnt signaling protects $3 \mathrm{~T} 3-\mathrm{LI}$ preadipocytes from apoptosis through induction of insulin-like growth factors. Biol Chem 2002, 277:38239-38244.

27. He B, Reguart N, You L, Mazieres J, Xu Z, Lee AY, Mikami I, McCormick $F$, Jablons DM: Blockade of Wnt-I signaling induces apoptosis in human colorectal cancer cells containing downstream mutations. Oncogene 2005, 24:3054-3058.

28. He B, You L, Uematsu K, Xu Z, Lee AY, Matsangou M, McCormick F, Jablons DM: A monoclonal antibody against Wnt-I induces apoptosis in human cancer cells. Neoplasia 2004, 6:7-14.

29. Rhee CS, Sen M, Lu D, Wu C, Leoni L, Rubin J, Corr M, Carson DA: Wnt and frizzled receptors as potential targets for immunotherapy in head and neck squamous cell carcinomas. Oncogene 2002, 2 I:6598-6605.

30. Murakami H, Sanderson ND, Nagy P, Marino PA, Merlino G, Thorgeirsson SS: Transgenic mouse model for synergistic effects of nuclear oncogenes and growth factors in tumorigenesis: interaction of c-myc and transforming growth factor alpha in hepatic oncogenesis. Cancer Res 1993, 53:1719-1723.

3I. Sandgren EP, Quaife CJ, Pinkert CA, Palmiter RD, Brinster RL: Oncogene-induced liver neoplasia in transgenic mice. Oncogene 1989, 4:715-724.

32. Shachaf CM, Kopelman AM, Arvanitis C, Karlsson A, Beer S, Mandl S, Bachmann MH, Borowsky AD, Ruebner B, Cardiff RD, et al.: MYC inactivation uncovers pluripotent differentiation and tumour dormancy in hepatocellular cancer. Nature 2004, 43I:III2-III7.

33. He SQ, Rehman H, Gong MG, Zhao YZ, Huang ZY, Li CH, Zhang WG, Chen XP: Inhibiting survivin expression enhances TRAILinduced tumoricidal activity in human hepatocellular carcinoma via cell cycle arrest. Cancer Biol Ther 2007, 6: I247-I257.

34. Korinek V, Barker N, Morin PJ, van Wichen D, de Weger R, Kinzler $\mathrm{KW}$, Vogelstein B, Clevers $\mathrm{H}$ : Constitutive transcriptional activation by a beta-catenin-Tcf complex in APC-/- colon carcinoma. Science 1997, 275: 1784-1787.

35. El-Bassiouni A, Nosseir M, Zoheiry M, El-Ahwany E, Ghali A, ElBassiouni N: Immunohistochemical expression of CD95 (Fas), c-myc and epidermal growth factor receptor in hepatitis C virus infection, cirrhotic liver disease and hepatocellular carcinoma. Apmis 2006, I I 4:420-427.

36. Moon WS, Tarnawski AS: Nuclear translocation of survivin in hepatocellular carcinoma: a key to cancer cell growth? Hum Pathol 2003, 34: I I19-1 I 26.

37. Sato $Y$, Itoh F, Hareyama M, Satoh M, Hinoda $Y$, Seto M, Ueda R, Imai $\mathrm{K}$ : Association of cyclin DI expression with factors correlated with tumor progression in human hepatocellular carcinoma. J Gastroenterol 1999, 34:486-493.

\begin{tabular}{|l|}
\hline Publish with Bio Med Central and every \\
scientist can read your work free of charge \\
"BioMed Central will be the most significant development for \\
disseminating the results of biomedical research in our lifetime. " \\
Sir Paul Nurse, Cancer Research UK \\
Your research papers will be: \\
• available free of charge to the entire biomedical community \\
• peer reviewed and published immediately upon acceptance \\
• cited in PubMed and archived on PubMed Central \\
• yours - you keep the copyright \\
Submit your manuscript here: \\
http://www.biomedcentral.com/info/publishing_adv.asp
\end{tabular}

